\title{
A Supramolecular Strategy for Enhancing Photochirogenic Performance through Host/Guest Modification: Dicationic $\gamma$ - Cyclodextrin-Mediated Photocyclodimerization of 2,6- Anthracenedicarboxylate
}

Qian Wang, ${ }^{*}, \dagger$ Wenting Liang, ${ }^{\ddagger}$ Xueqin Wei, ${ }^{\S}$ Wanhua Wu, ${ }^{\#}$ Yoshihisa Inoue, ${ }^{*, \|}$ Cheng Yang,*,\# and $\mathrm{Yu} \mathrm{Liu}{ }^{*}, \perp$

\footnotetext{
${ }^{\dagger}$ Tianjin Key Laboratory of Food Biotechnology, School of Biotechnology and Food Science, Tianjin University of Commerce, Tianjin 300134, China

\# Institute of Environmental Science, Department of Chemistry, Shanxi University, Taiyuan 030006, China

$\S$ School of Pharmacy, Guangxi Medical University, Nanning 530021, China

\# Key Laboratory of Green Chemistry \& Technology, College of Chemistry, State Key Laboratory of Biotherapy, West China Medical Center, and Healthy Food Evaluation Research Center, Sichuan University, Chengdu 610064, China

" Department of Applied Chemistry, Osaka University, Yamada-oka 2-1, Suita 565-0871, Japan

${ }^{\perp}$ College of Chemistry, State Key Laboratory of Elemento-Organic Chemistry, Nankai University, Tianjin 300071, China; Collaborative Innovation Center of Chemical Science and Engineering, Tianjin 300072, China E-mails: qwang@tjcu.edu.cn; inoue@chem.eng.osaka-u.ac.jp; yangchengyc@scu.edu.cn; yuliu@nankai.edu.cn
} 


\section{Table of Contents}

page

1. Experimental

Materials S3

Instruments

Photolyses

S3

Syntheses of modified $\gamma$-CD hosts

2. NMR and HRMS spectra $\quad$ S4

3. Complexation behavior examined by ${ }^{1} \mathrm{H}$ NMR spectroscopy $\quad$ S10

4. Job analysis for confirming the 1:2 complex stoichiometry S10

5. Determination of the association constants $\quad$ S10

6. UV-vis spectrum of the 1:2 complex deduced by spectral subtraction S10

7. Fluorescence spectrum of the 1:1 complex deduced by spectral subtraction S11

8. Representative chiral HPLC chromatograms $\quad$ S12

9. Population of and light absorption by free AD, 1:1 and 1:2 complexes S13

10. Enantiodifferentiating photocyclodimerization of AD mediated by native and
modified $\gamma$-CDs

11. Wavelength-dependent yield and ee of anti S15

12. Host-guest interactions in the precursor complex of AD with dicationic $\gamma$-CD host S15

$\begin{array}{ll}\text { References } & \text { S15 }\end{array}$ 


\section{Experimental}

Materials. Native $\gamma-\mathrm{CD}$ and other reagents were purchased from Wako Pure Chemical Corp. and used as received. 6- $O$-Tosyl- $\gamma-\mathrm{CD}^{1}$ and $6^{\mathrm{A}}, 6^{\mathrm{E}}$-dideoxy- $6^{\mathrm{A}}, 6^{\mathrm{E}}$ diazido- $\gamma-\mathrm{CD}^{2}$ were prepared by the literature procedures. Hosts 1 and 2 were prepared by the procedures reported previously, ${ }^{3}$ while hosts 3-5 were synthesized as described below.

Instruments. NMR and MS spectra were obtained with JEOL JNM-EX 400 and JEOL JMS-DX303 spectrometer, respectively. UV-vis, fluorescence and circular dichroism spectra were recorded on JASCO V-560 spectrophotometer, JASCO FP-6500 luminescence spectrometer and JASCO J810 spectropolarimeter, respectively, all equipped with a UNISOKU USP-203CD cryostat.

Photolyses and product analyses. All photoirradiations were carried out in a UNISOKU cryostat set at different temperatures. Sample solution of AD $(0.4 \mathrm{mM})$ and $\gamma$-CD host $(2 \mathrm{mM})$ in a quartz cell was deaerated by $\mathrm{N}_{2}$ bubbling and then irradiated at different wavelengths using an ultrahigh-pressure xenon lamp equipped with a band-pass filter $(\mathrm{fwhm}=10 \mathrm{~nm})$. Chiral HPLC analysis of the irradiated sample was performed using a tandem Cosmosil 5C18-AR- II $(4.6 \varphi \times 100 \mathrm{~mm}$, Nacalai tesque $)$ plus chiral OJ-RH (4.6 $\varphi \times 150 \mathrm{~mm}$, Daicel) column eluted with a 76:24:0.1 mixture of distilled water, acetonitrile and trifluoroacetic acid at $40{ }^{\circ} \mathrm{C}$. Chemical yields and $e e$ values were determined from the peak area of HPLC chromatogram monitored by a fluorescence detector.

Synthesis of host 3. 6-TsO- $\gamma$-CD (300 mg, $0.207 \mathrm{mmol})$ and $N, N$-diethyl-1,4-butanediamine $(1 \mathrm{~mL}, 0.841 \mathrm{~g}, 5.83$ mmol) was mixed, and the mixture was heated to $80{ }^{\circ} \mathrm{C}$ in an oil bath and stirred for $12 \mathrm{~h}$ at that temperature under $\mathrm{N}_{2}$. Then, the hot solution was poured dropwise onto acetone $(100 \mathrm{~mL})$ with stirring to give a white precipitate. The white precipitate collected by centrifugation was dissolved in water and freeze-dried to obtain compound $\mathbf{3}$ as a white powder $(211 \mathrm{mg})$ in $72 \%$ yield. ${ }^{1} \mathrm{H}$ NMR $\left(400 \mathrm{MHz}, \mathrm{D}_{2} \mathrm{O}\right)$ : $5.01(8 \mathrm{H}, \mathrm{m}), 3.85-3.47(46 \mathrm{H}, \mathrm{m}), 3.33(1 \mathrm{H}, \mathrm{t}), 3.04-2.95$
$(6 \mathrm{H}, \mathrm{m}), 2.70(1 \mathrm{H}, \mathrm{m}), 2.55(2 \mathrm{H}, \mathrm{m}), 1.59(2 \mathrm{H}, \mathrm{m}), 1.46(2 \mathrm{H}$, $\mathrm{m}), 1.15(6 \mathrm{H}, \mathrm{t}) .{ }^{13} \mathrm{C}$ NMR $\left(100 \mathrm{MHz}, \mathrm{D}_{2} \mathrm{O}\right): 101.6,80.4$, 72.8, 72.2, 71.7, 60.1, 51.4, 49.4, 48.1, 47.0, 25.7, 21.6, 8.5. HRMS (ESI-QFT) $m / z$ : $[\mathrm{M}+2 \mathrm{H}]^{2+}$ Calcd for $\mathrm{C}_{56} \mathrm{H}_{100} \mathrm{~N}_{2} \mathrm{O}_{39}$ 1424.5903; Found 712.2949 (1424.5898 as a monocation).

Synthesis of host 4. $6^{\mathrm{A}}, 6^{\mathrm{E}}$-Dideoxy- $6^{\mathrm{A}}, 6^{\mathrm{E}}$-diazido- $\gamma$-CD (400 mg, $0.297 \mathrm{mmol})$ and triphenylphosphine $(235 \mathrm{mg}$, $0.896 \mathrm{mmol})$ were dissolved in dry DMF $(10 \mathrm{~mL})$ and the mixture was stirred for $48 \mathrm{~h}$ at room temperature. To the resultant was added with stirring $28 \%$ aqueous ammonia ( 3 $\mathrm{mL}$ ), and the solution was stirred for $5 \mathrm{~h}$ and then poured onto cool acetone $(100 \mathrm{~mL})$ to give a precipitate. The precipitate was collected by filtration and then purified by recrystallization from a mixture of water and acetone to give compound 4 as a white powder $(307 \mathrm{mg})$ in $80 \%$ yield. ${ }^{1} \mathrm{H}$ NMR (600 MHz, $\left.\mathrm{D}_{2} \mathrm{O}\right): 5.02(8 \mathrm{H}, \mathrm{m}), 3.84-3.75(28 \mathrm{H}, \mathrm{m})$, 3.55-3.47 $(14 \mathrm{H}, \mathrm{m}), 3.38(2 \mathrm{H}, \mathrm{m}), 3.08(2 \mathrm{H}, \mathrm{m}), 2.85(2 \mathrm{H}$, m). ${ }^{13} \mathrm{C}$ NMR (100 MHz, $\left.\mathrm{D}_{2} \mathrm{O}\right): 101.7,101.5,101.2,80.3$, 79.8, 72.8, 72.3, 72.2, 72.1, 72.0, 71.7, 70.6, 60.2, 60.1, 40.9 . HRMS (ESI-QFT) $m / z$ : $[\mathrm{M}+2 \mathrm{H}]^{2+}$ Calcd for $\mathrm{C}_{48} \mathrm{H}_{84} \mathrm{~N}_{2} \mathrm{O}_{38}$ 1296.4702; Found 648.2348 (1296.4696 as a monocation).

Synthesis of host 5. $6^{\mathrm{A}}, 6^{\mathrm{D}}$-Dideoxy- $6^{\mathrm{A}}, 6^{\mathrm{D}}$-diamino- $\gamma$-CD (300 mg, $0.232 \mathrm{mmol}$ ), 1H-pyrazole carboxamidine hydrochloride (1.0 g, $6.82 \mathrm{mmol})$ and $N, N$-diisopropylethylamine $(2.0 \mathrm{~mL}, 1.56 \mathrm{~g}, 12.1 \mathrm{mmol})$ were mixed in water $(3.0 \mathrm{~mL})$. The mixture was stirred for $48 \mathrm{~h}$ at room temperature, and then poured dropwise onto acetone (100 $\mathrm{mL}$ ) to give a precipitate. The precipitate was collected by centrifugation, washed three times with acetone $(30 \mathrm{~mL})$, and then dissolved in water and freeze-dried to give host $\mathbf{5}$ as a pale white powder $(239 \mathrm{mg})$ in $75 \%$ yield. ${ }^{1} \mathrm{H}$ NMR $\left(400 \mathrm{MHz}, \mathrm{D}_{2} \mathrm{O}\right): 5.00-4.95(8 \mathrm{H}, \mathrm{m}), 3.86(2 \mathrm{H}, \mathrm{m}), 3.79-$ $3.70(24 \mathrm{H}, \mathrm{m}), 3.52-3.49(10 \mathrm{H}, \mathrm{m}), 3.45-3.38(12 \mathrm{H}, \mathrm{m}) .{ }^{13} \mathrm{C}$ NMR $\left(100 \mathrm{MHz}, \mathrm{D}_{2} \mathrm{O}\right): 157.8,101.8,101.6,101.4,81.7$, 80.5, 80.4, 72.8, 72.5, 72.2, 72.1, 72.0, 71.9, 71.8, 71.7, 70.3, 60.4, 60.2, 60.1, 42.1. HRMS (ESI-TOF) $\mathrm{m} / \mathrm{z}:[\mathrm{M}+\mathrm{H}]^{+}$ Calcd for $\mathrm{C}_{50} \mathrm{H}_{87} \mathrm{~N}_{6} \mathrm{O}_{38}$ 1379.5060; Found 1379.5072. ${ }^{4}$ 


\section{NMR and HRMS spectra}

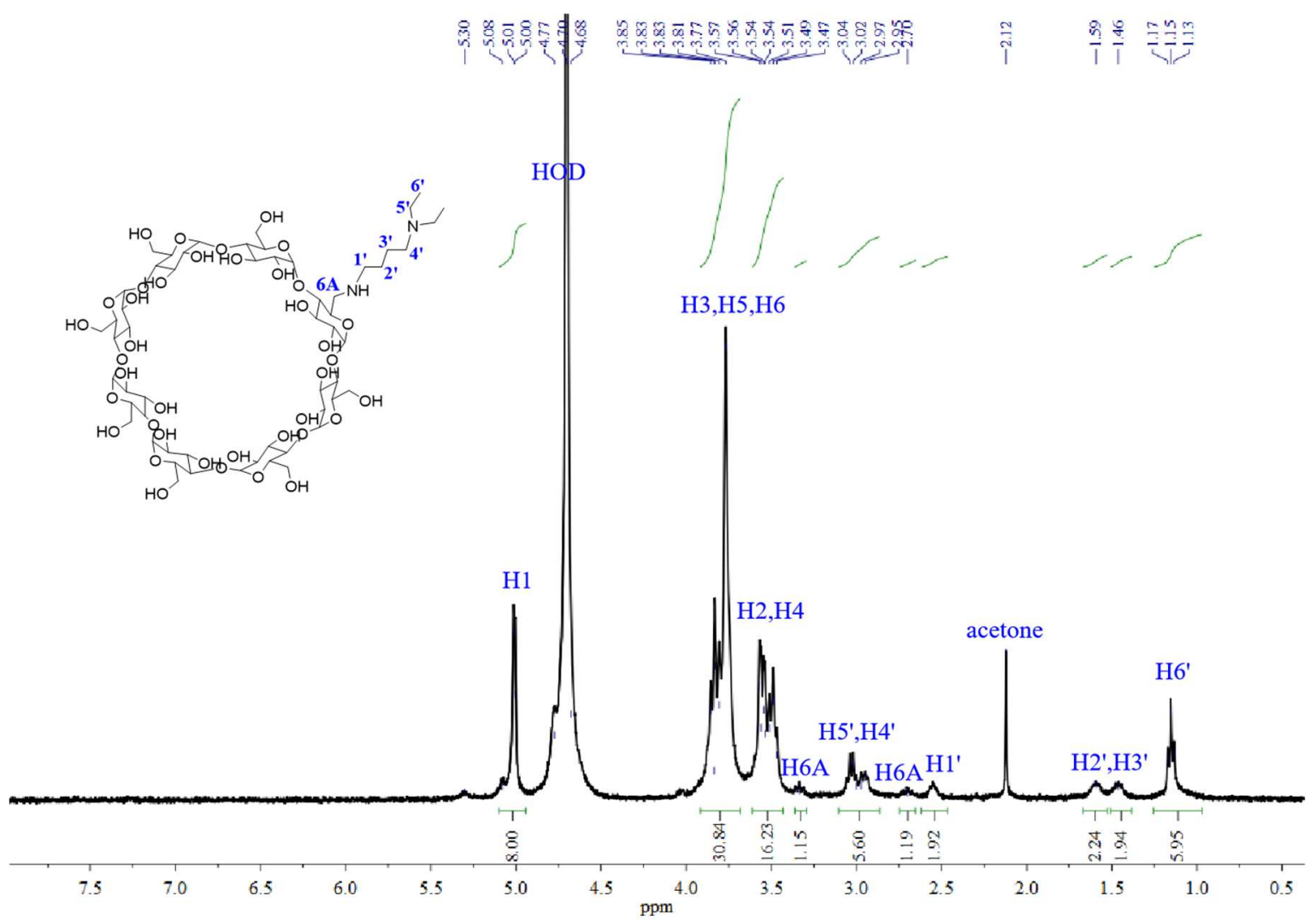

Figure S1. ${ }^{1} \mathrm{H}$ NMR $(400 \mathrm{MHz})$ spectrum of host 3 in $\mathrm{D}_{2} \mathrm{O}$ at ambient temperature.

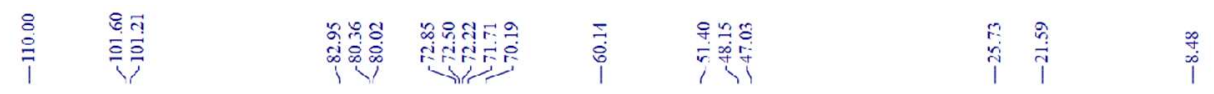

C2, C3, C5

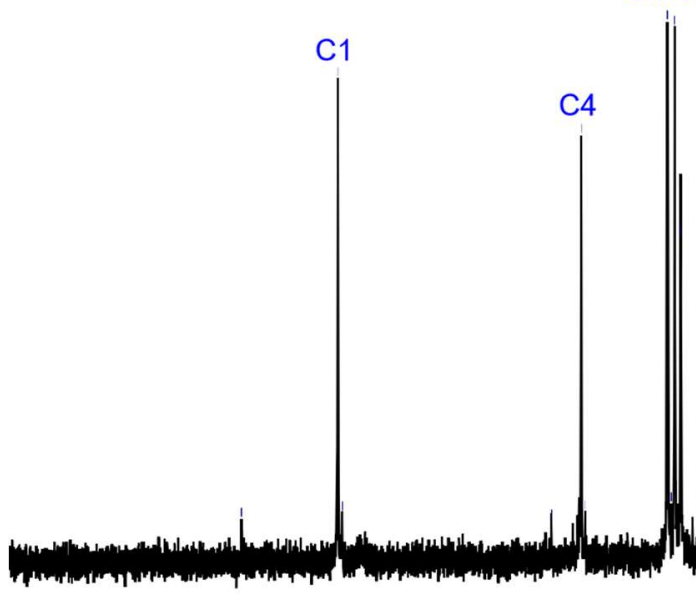

$\begin{array}{llllllllll}30 & 125 & 120 & 115 & 110 & 105 & 100 & 95 & 90 & 85\end{array}$

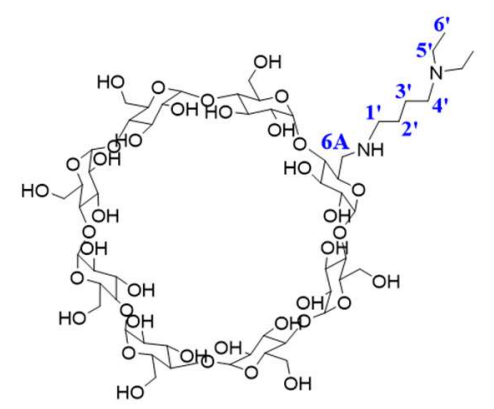

Figure S2. ${ }^{13} \mathrm{C}$ NMR $(100 \mathrm{MHz})$ spectrum of host 3 in $\mathrm{D}_{2} \mathrm{O}$ at ambient temperature. 


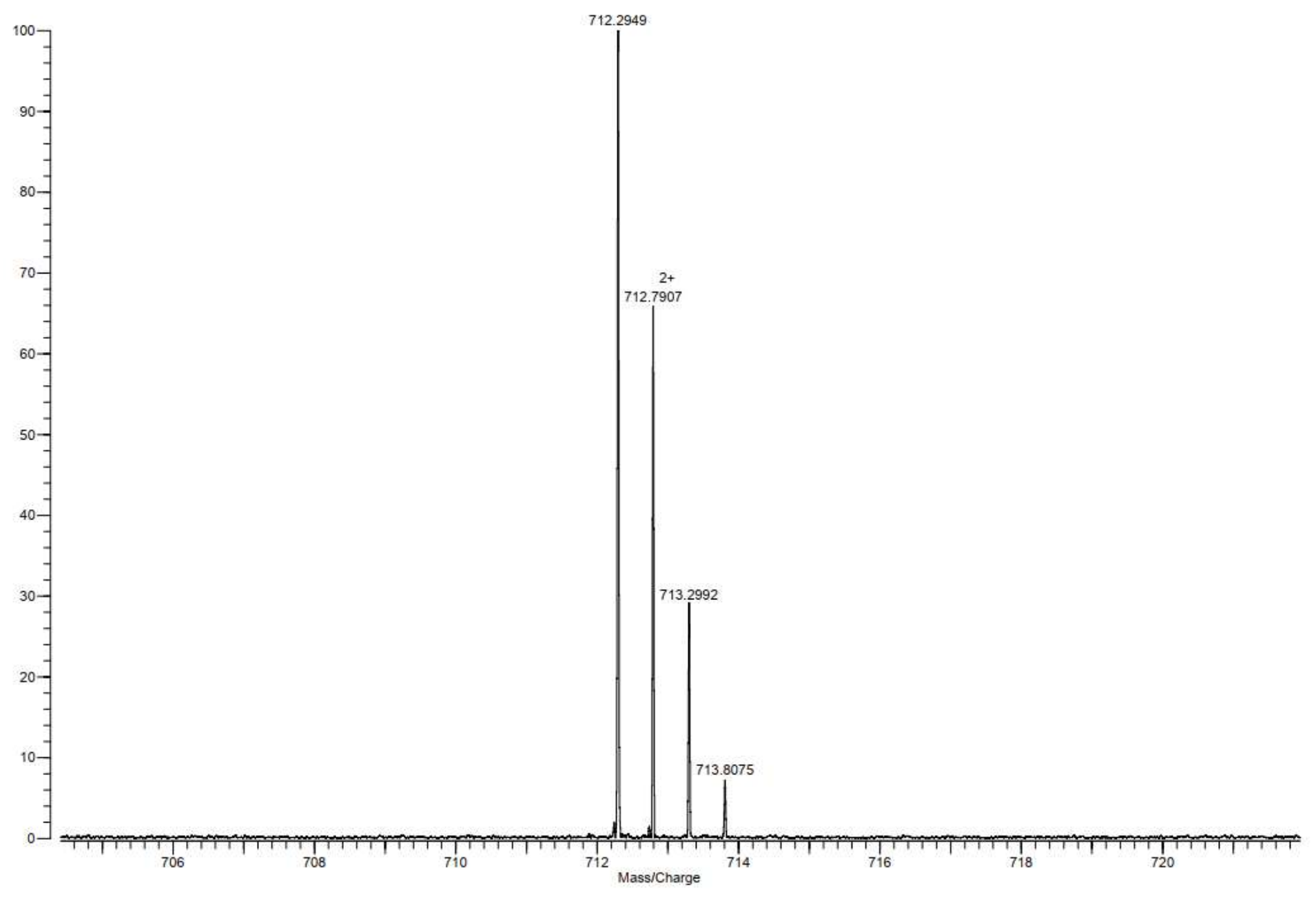

Figure S3. High-resolution mass spectrum of host $\mathbf{3}$. 


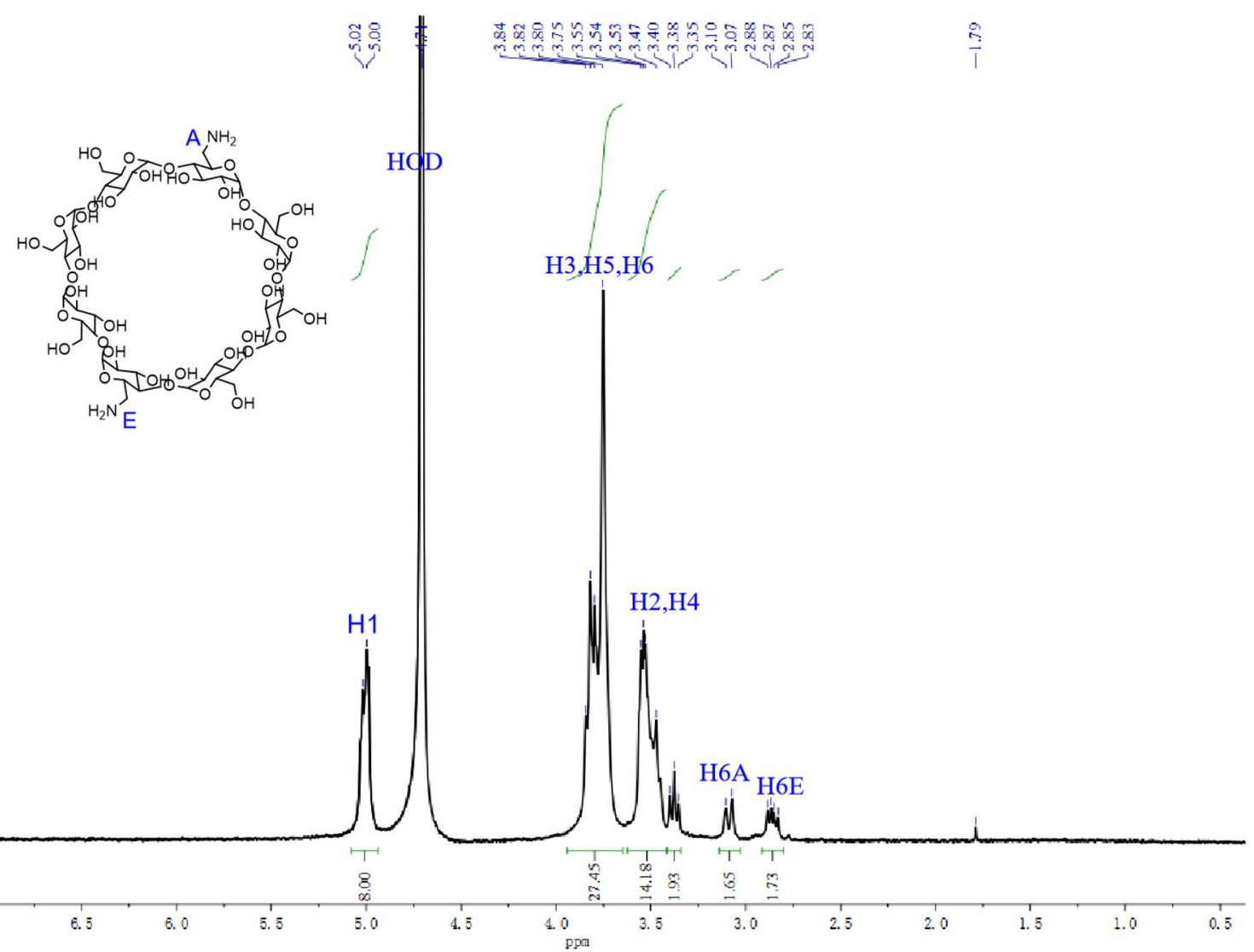

Figure S4. ${ }^{1} \mathrm{H}$ NMR $(600 \mathrm{MHz})$ spectrum of $6^{\mathrm{A}}, 6^{\mathrm{E}}-$ dideoxy- $6^{\mathrm{A}}, 6^{\mathrm{E}}$-diamino- $\gamma-\mathrm{CD}(4)$ in $\mathrm{D}_{2} \mathrm{O}$ at ambient temperature.

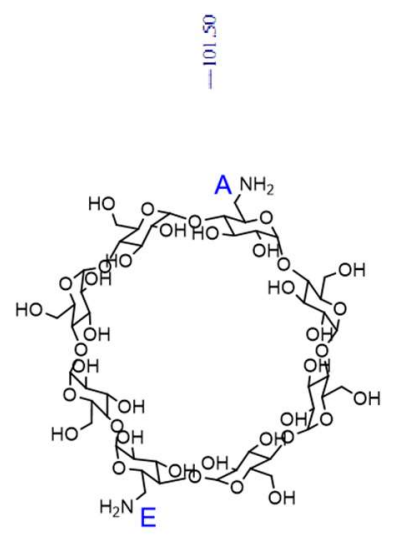

$\stackrel{1}{1}$

\section{$\mathrm{C} 2, \mathrm{C} 3, \mathrm{C} 5$}

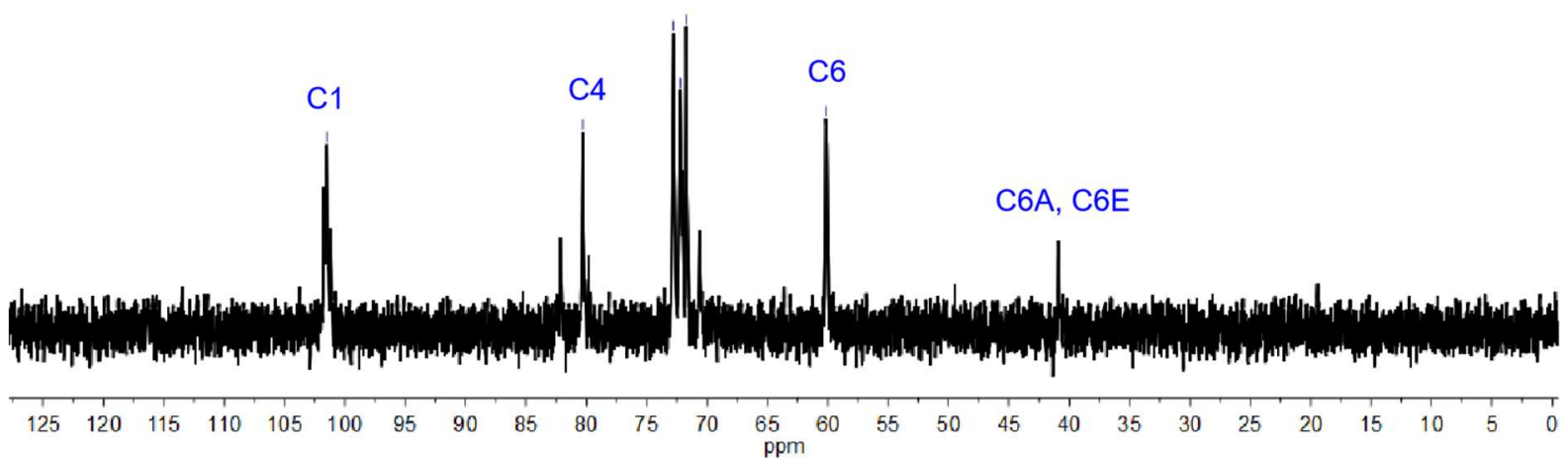

Figure S5. ${ }^{13} \mathrm{C}$ NMR $(100 \mathrm{MHz})$ spectrum of $6^{\mathrm{A}}, 6^{\mathrm{E}}$-dideoxy- $6^{\mathrm{A}}, 6^{\mathrm{E}}$-diamino- $\gamma$-CD $(4)$ in $\mathrm{D}_{2} \mathrm{O}$ at ambient temperature. 


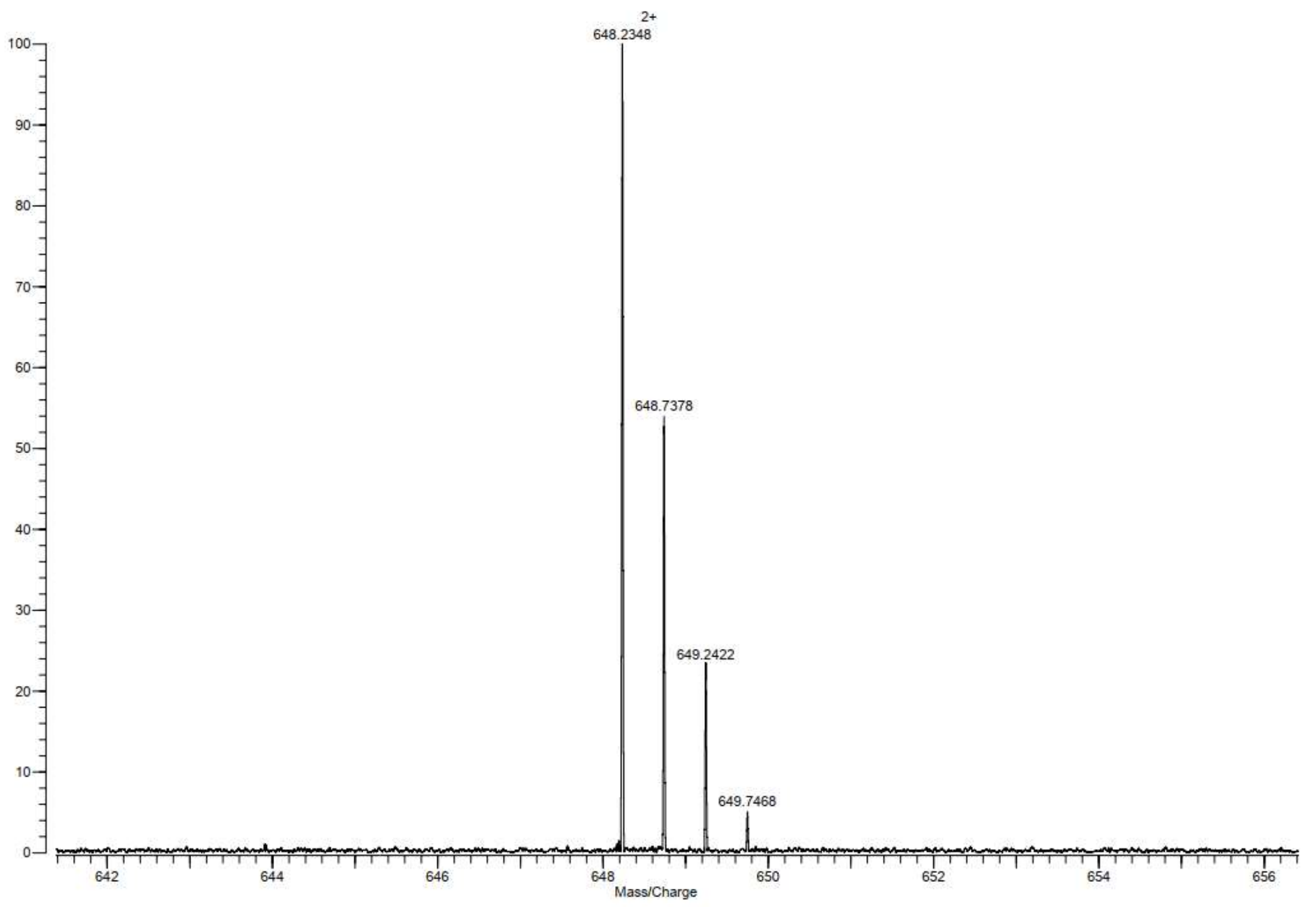

Figure S6. High-resolution mass spectrum of $6^{\mathrm{A}}, 6^{\mathrm{E}}$-dideoxy- $6^{\mathrm{A}}, 6^{\mathrm{E}}$-diamino- $\gamma$-CD (4). 


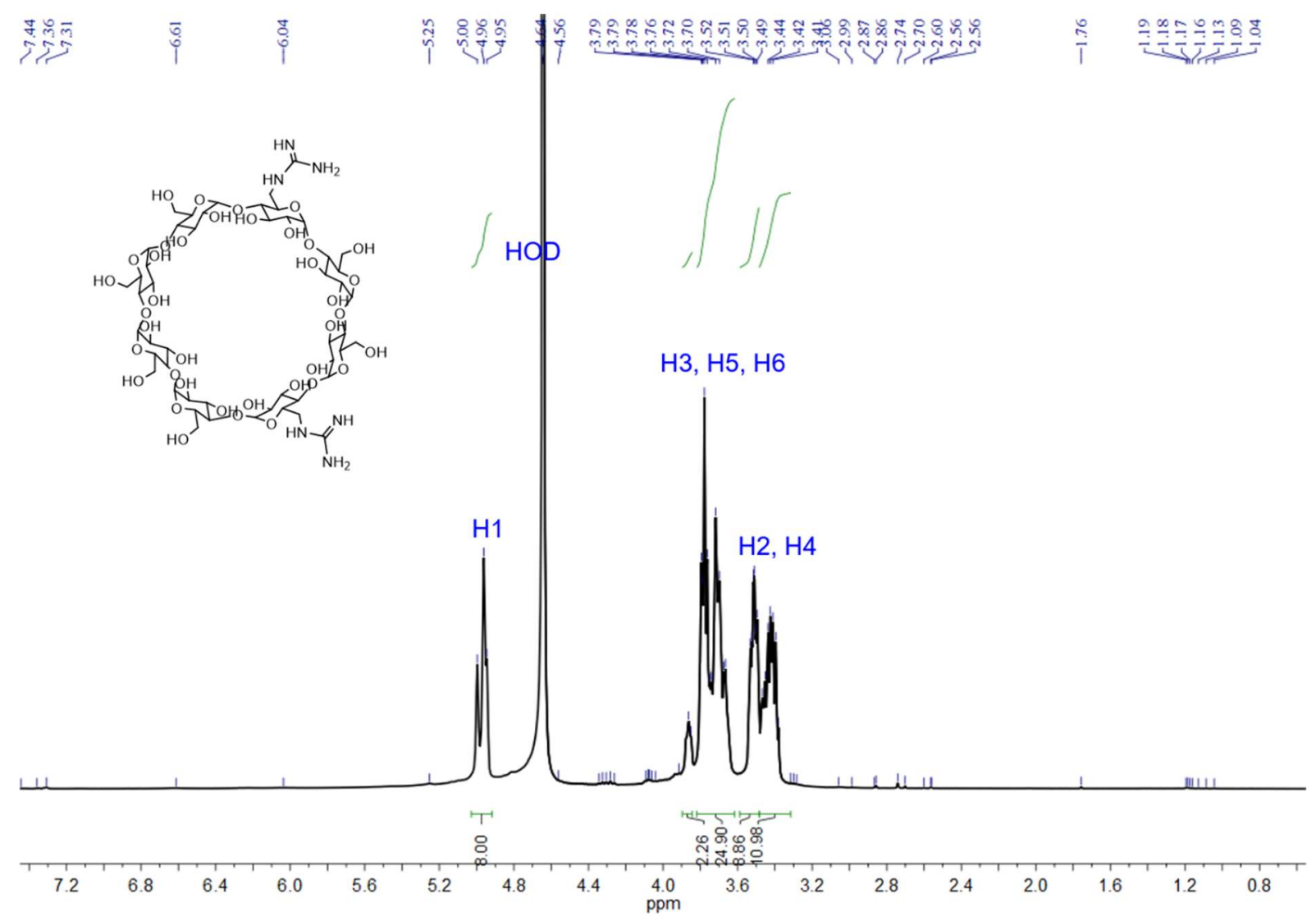

Figure S7. ${ }^{1} \mathrm{H}$ NMR $(400 \mathrm{MHz})$ spectrum of $6^{\mathrm{A}}, 6^{\mathrm{D}}-$ dideoxy- $6^{\mathrm{A}}, 6^{\mathrm{D}}$-diguanidino- $\gamma-\mathrm{CD}(\mathbf{5})$ in $\mathrm{D}_{2} \mathrm{O}$ at ambient temperature.
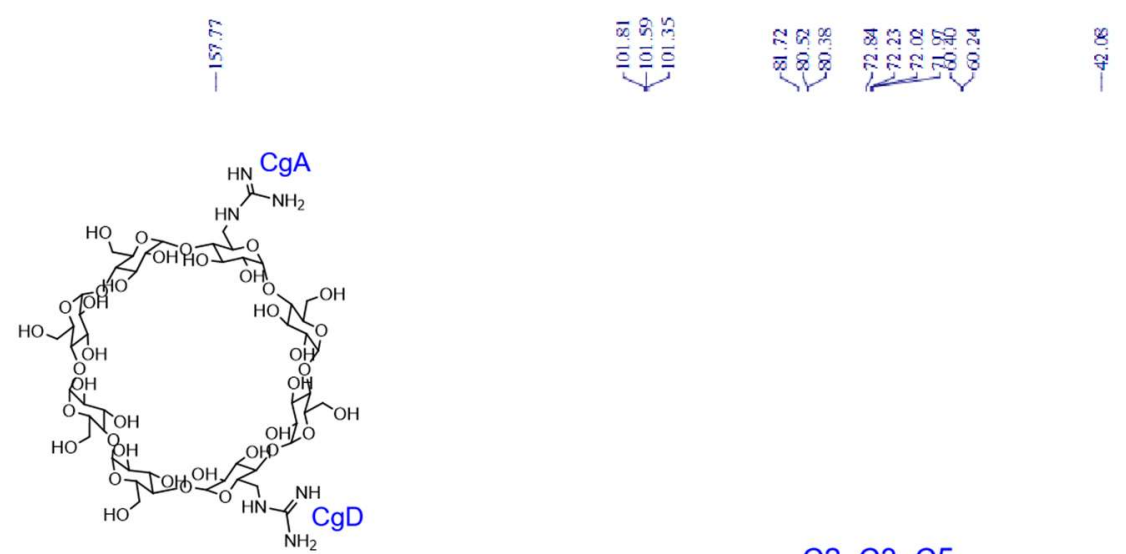

C2, C3, C5

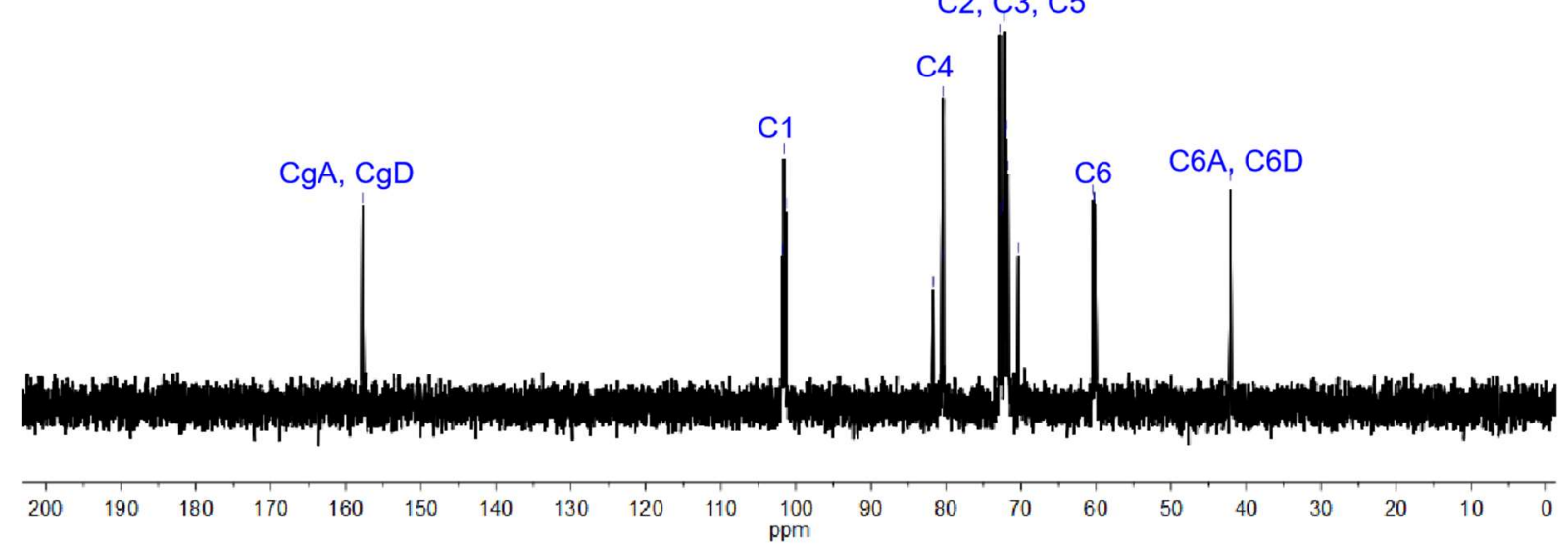

Figure S8. ${ }^{13} \mathrm{C}$ NMR $(100 \mathrm{MHz})$ spectrum of $6^{\mathrm{A}}, 6^{\mathrm{D}}$-dideoxy- $6^{\mathrm{A}}, 6^{\mathrm{D}}$-diguanidino- $\gamma$-CD $(\mathbf{5})$ in $\mathrm{D}_{2} \mathrm{O}$ at ambient temperature. 


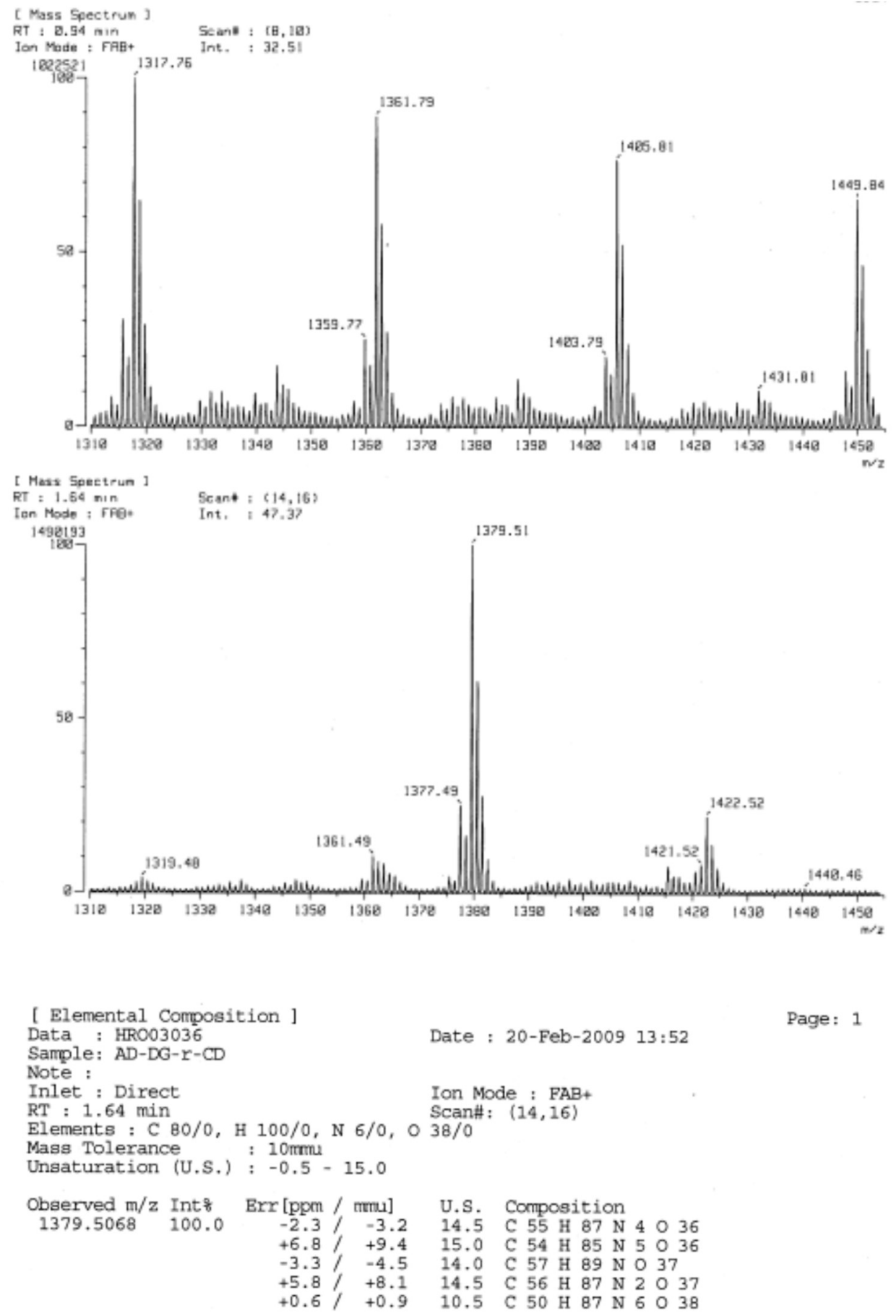

Figure S9. High-resolution mass spectrum of $6^{\mathrm{A}}, 6^{\mathrm{D}}$-dideoxy- $6^{\mathrm{A}}, 6^{\mathrm{D}}$-diguanidino- $\gamma$-CD (5). ${ }^{4}$ 


\section{Complexation behavior examined by ${ }^{1} \mathrm{H}$ NMR spectroscopy}

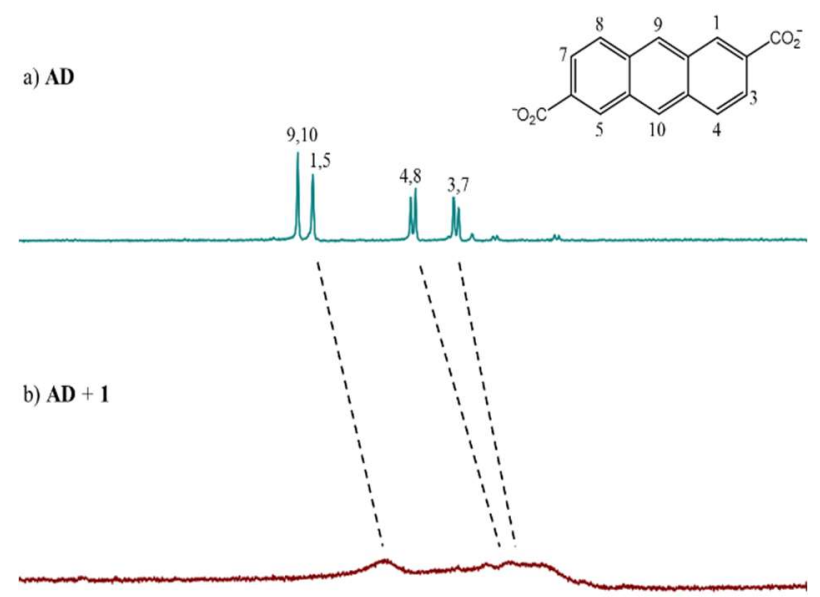

$\begin{array}{llllllllllllllllllllllll}9.8 & 9.6 & 9.4 & 9.2 & 9.0 & 8.8 & 8.6 & 8.4 & 8.2 & 8.0 & 7.8 & 7.6 & 7.4 & 7.2 & 7.0 & 6.8 & 6.6 & 6.4 & 6 .\end{array}$

Figure 10. The ${ }^{1} \mathrm{H}$ NMR spectra of (a) free AD $(2 \mathrm{mM})$ and (b) AD (4 mM) in the presence of host $1(4 \mathrm{mM})$ in $\mathrm{pD} 9$ $\mathrm{D}_{2} \mathrm{O}$ buffer solution at $25^{\circ} \mathrm{C}$.

Discussion. All of the proton signals of AD were upfieldshifted with significant peak-broadening upon addition of host 1 , suggesting coexistence of multiple species and slow exchange of AD between the free and complexed species on the NMR timescale.

\section{Job analysis for confirming the $1: 2$ complex stoichiometry}

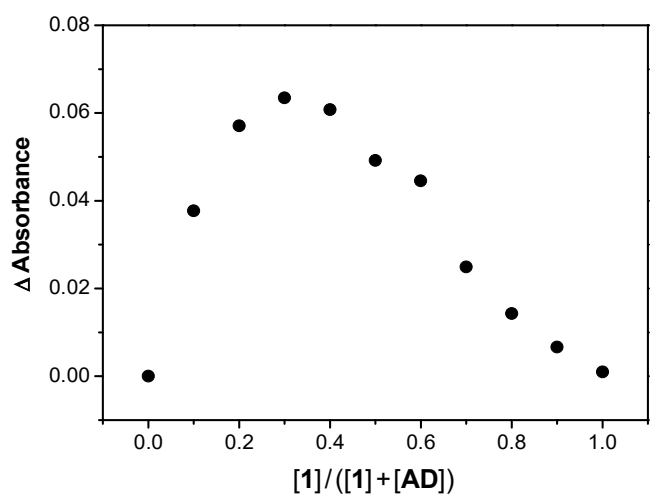

Figure S11. UV-vis spectral Job plot of the absorbance changes at $379 \mathrm{~nm}$ as a function of the molar fraction $(x)$ of host $\mathbf{1}$, where the total concentration of $\mathbf{A D}$ and $\mathbf{1}$ was kept constant at $0.4 \mathrm{mM}$ in a pH 9 phosphate buffer $(66.7 \mathrm{mM})$ at $25^{\circ} \mathrm{C}$. The absorbance change reached the top at $x=0.33$, indicating that the major species in the solution is a $1: 2$ complex under the conditions employed.

\section{Determination of the association constants}

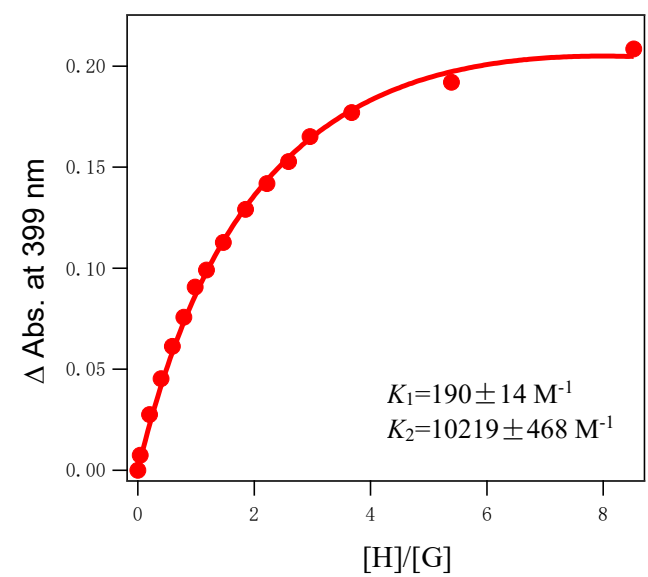

Figure S12. The nonlinear least-square-means fit to the stepwise $1: 1$ and 1:2 complexation of the UV-vis spectral changes observed upon titration of AD $(0.2 \mathrm{mM})$ with host $1(0-2.265 \mathrm{mM})$ shown in Figure 1 (main text) to determine $K_{1}=190 \pm 14 \mathrm{M}^{-1}$ and $K_{2}=10200 \pm 500 \mathrm{M}^{-1}$ in a $\mathrm{pH} 9$ phosphate buffer $(66.7 \mathrm{mM})$ at $25^{\circ} \mathrm{C}$.

\section{UV-vis spectrum of the 1:2 complex deduced by spectral subtraction}

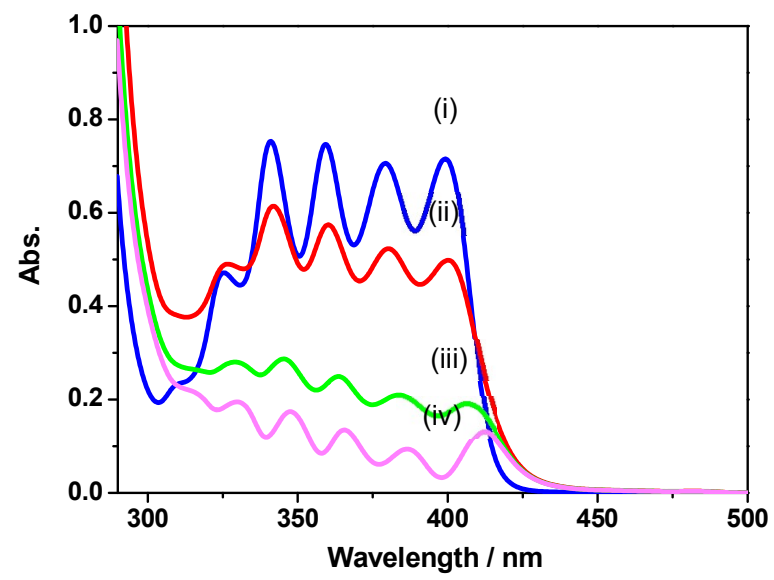

Figure S13. (i) UV-vis spectrum of AD $(0.2 \mathrm{mM})$; (ii) UVvis spectrum of AD $(0.2 \mathrm{mM})$ in the presence of host $\mathbf{1}$ $(2.265 \mathrm{mM})$; (iii) the subtraction spectrum obtained by the operation: spectrum (ii) - spectrum (i) $\times 0.456$; (iv) the subtraction spectrum obtained by the operation: spectrum (iii) - spectrum (i) $\times 0.19$; see below for detail.

Discussion. The significant difference in the UV-vis spectra of AD measured in the presence and absence of host $\mathbf{1}$ (Figure S13, spectra (ii) and (i), respectively) and the pseudo-isosbestic point observed upon UV-vis spectral titration (Figure 1a in the main text) as well as the population of free $\mathbf{A D}$ and 1:1 and 1:2 complexes obtained below in Table $\mathrm{S} 1$ enabled us to deduce a reasonable UV-vis spectrum of the 1:2 complex, which was considered to be significantly red-shifted compared to that of free AD.

To this end, we first subtracted the contribution of free AD (45.6\%; see Table S1) to the total absorbance from the 
UV-vis spectrum of AD $(0.2 \mathrm{mM})$ in the presence of $\mathbf{1}(2.265$ $\mathrm{mM}$ ) to obtain the subtraction spectrum (iii), which however still contains the contribution of the $1: 1$ complex $(19.0 \%)$ in addition to the $1: 2$ complex (35.4\%). Then, we assumed that the UV-vis spectrum of the 1:1 complex is practically identical to that of free AD, because the fluorescence spectrum of the 1:1 complex did not suffer any appreciable peak shifts (though more weakly fluorescing) upon 1:1 complexation with 1 (Figure S14d) and the pseudoisosbestic point was maintained throughout the titration (Figure 1a in the main text). This approximation enabled us to gain a plausible UV-vis spectrum (iv) of the 1:2 complex by subtracting the UV-vis spectrum of AD scaled by 0.19 from the spectrum (iii). In the spectrum of the 1:2 complex thus obtained, the $0-0$ band of the lowest-energy ${ }^{1} \mathrm{~L}_{b}$ transition is considerably red-shifted from $399.2 \mathrm{~nm}(25050$ $\left.\mathrm{cm}^{-1}\right)$ to $411.8 \mathrm{~nm}\left(24284 \mathrm{~cm}^{-1}\right)$ upon $1: 2$ complexation, indicating stabilization of $9.2 \mathrm{~kJ} \mathrm{~mol}^{-1}$ by the $\pi-\pi$ stacking of two ADs in a $\gamma$-CD cavity.

7. Fluorescence spectrum of the 1:1 complex deduced by spectral subtraction
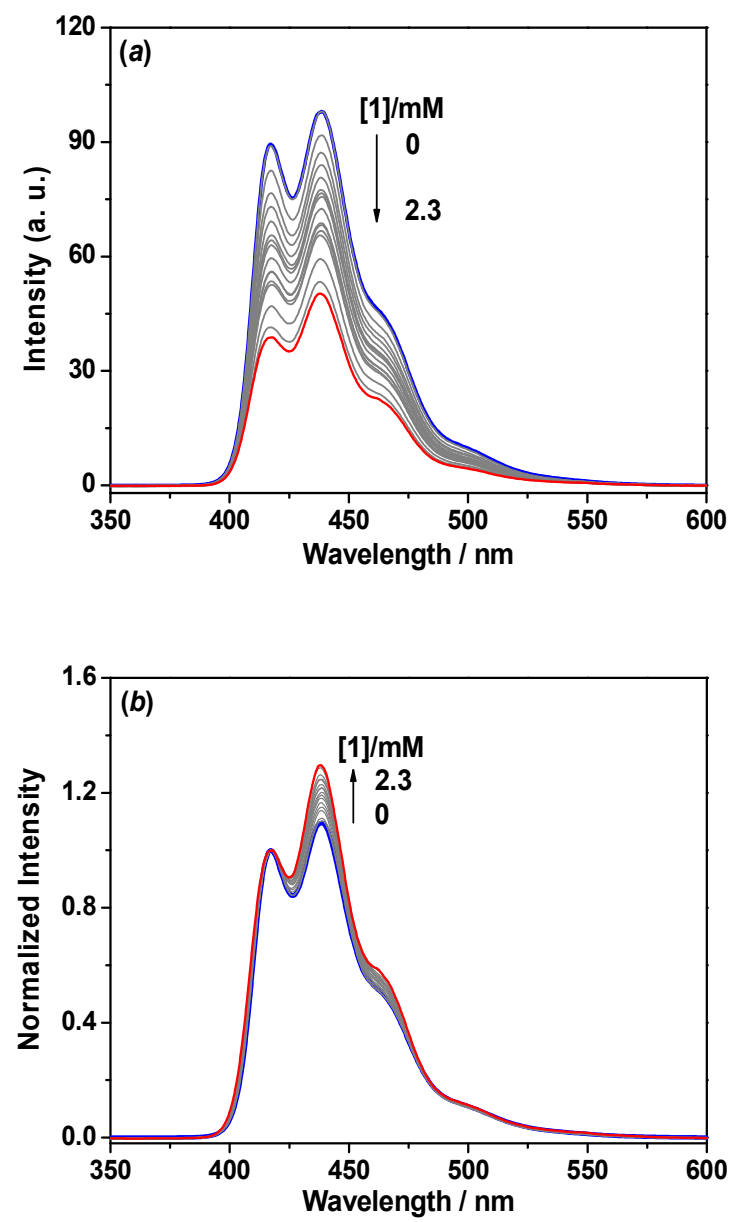
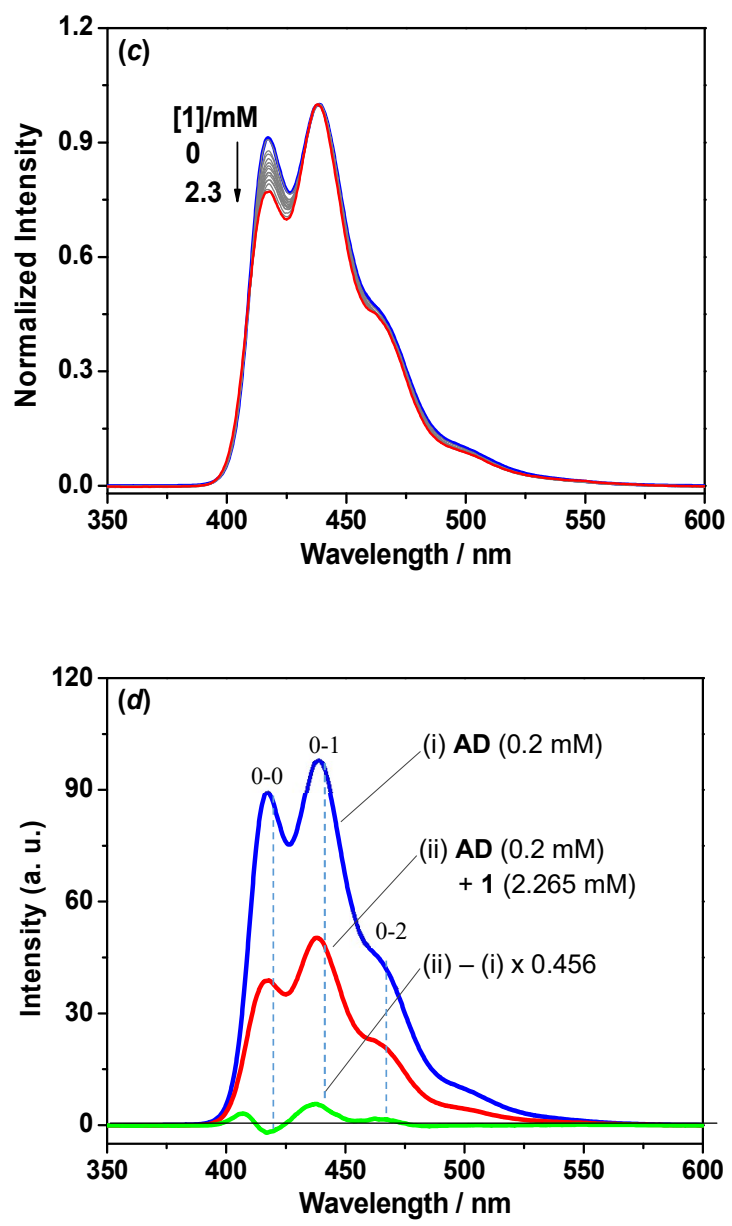

Figure S14. (a) Fluorescence spectral changes of $0.2 \mathrm{mM}$ AD in a pH 9 aqueous phosphate buffer solution $(66.7 \mathrm{mM})$ at $25{ }^{\circ} \mathrm{C}$ placed in a $10-\mathrm{mm}$ quartz cell upon stepwise addition of host 1 at $0,0.008,0.040,0.080,0.119,0.158$, $0.197,0.236,0.294,0.370,0.444,0.518,0.592,0.735,1.078$, 1.705 and $2.265 \mathrm{mM}$. Excitation at $275 \mathrm{~nm}$. (b) Fluorescence spectra normalized at the 0-0 band. (c) Fluorescence spectra normalized at the $0-1$ band. (d) Fluorescence spectra of (i) $0.2 \mathrm{mM}$ AD (blue) and (ii) $0.2 \mathrm{mM}$ AD plus $2.265 \mathrm{mM} 1$ (red) and the difference spectrum (green) obtained by subtracting the spectrum (i) multiplied by 0.456 (the fraction of photons absorbed by free AD in the solution, Table S1) from the spectrum (ii).

Discussion. Upon stepwise addition of host 1, the fluorescence of AD was gradually quenched to nearly a half of the original intensity at the highest concentration $(2.265$ $\mathrm{mM}$ ) (Figure S14a). For easier comparison of the spectral shape and shift, all the spectra were normalized at the $0-0$ and $0-1$ bands to afford two series of spectra shown in Figs. $\mathrm{S} 3 \mathrm{~b}$ and S3c, respectively. These normalized spectra reveal that (1) the peak (shoulder) positions do not vary $(\Delta \lambda \leq 1 \mathrm{~nm})$ upon addition of 1 of up to $2.265 \mathrm{mM}$, (2) the relative intensity of the 0-1 versus $0-0$ band gradually increases with increasing concentration of $\mathbf{1}$, and (3) no new emission is seen at $>500 \mathrm{~nm}$.

The lack of noticeable new emission at longer wavelengths, despite the significant red-shift observed in the UVvis spectrum due to the $\pi$-stacking 1:2 complexation (Figure S13), implies that, upon photoexcitation, a pair of ADs 
closely packed in a $\gamma$-CD cavity spontaneously cyclodimerizes without emitting light, as was the case with the photocyclodimerization of AC mediated by $\gamma-\mathrm{CD} .{ }^{5}$ This also means that the observed fluorescence originates solely from free AD and 1:1 complex.

In an attempt to speculate a reasonable fluorescence spectrum of the 1:1 complex by a more quantitative treatment of the observed spectra, we first calculated the population of free AD, 1:1 and 1:2 complexes in a solution of $0.2 \mathrm{mM} \mathrm{AD}$ and $2.265 \mathrm{mM}$ host 1 as 55.4:23.1:21.5, using the association constants $K_{1}=190 \mathrm{M}^{-1}$ and $K_{2}=10200 \mathrm{M}^{-1}$ obtained above in Figure S12. Assuming the same molar extinction coefficients for free $\mathbf{A D}$ and the 1:1 complex and a twice larger one for the 1:2 complex (i.e., $\varepsilon_{1: 2} \approx 2 \varepsilon_{\mathbf{A D}} \approx$ $\left.2 \varepsilon_{1: 1}\right)$, we evaluated the relative light absorption by these AD-containing species as 45.6:19.0:35.4 (Table S1). Since the $1: 2$ complex absorbs a significant fraction (35.4\%) of the total absorbed photons but is nonfluorescent, the fluorescence spectrum of the 1:1 complex is obtained by subtracting the spectrum of free AD scaled by a factor of 0.456 from that of the solution containing $0.2 \mathrm{mM} \mathbf{A D}$ and $2.265 \mathrm{mM} 1$, as illustrated in Figure S14d (green line). The spectrum obtained is somewhat over-subtracted near the $0-0$ band, for which the unequal relative intensity of the $0-0$ versus $0-1$ band (Figure S14c) and/or the assumption employed ( $\left.\varepsilon_{1: 2} \approx 2 \varepsilon_{\mathbf{A D}} \approx 2 \varepsilon_{1: 1}\right)$ would be jointly responsible. Nevertheless, the 0-1 and 0-2 bands appear to keep the original positions or be only slightly blue-shifted. It is also to note that, absorbing $19.0 \%$ of the total absorbed photons, the $1: 1$ complex fluoresces in a $5.8 \%$ intensity (at the $0-1$ band) relative to that of free AD (spectrum (i)), indicating that AD becomes ca. 3-fold less fluorescent when accommodated alone in the hydrophobic environment of CD cavity, as was the case with the 1:1 complex of $\mathbf{A C}$ with native $\gamma-\mathrm{CD} .^{5}$

\section{Representative Chiral HPLC chromatograms}

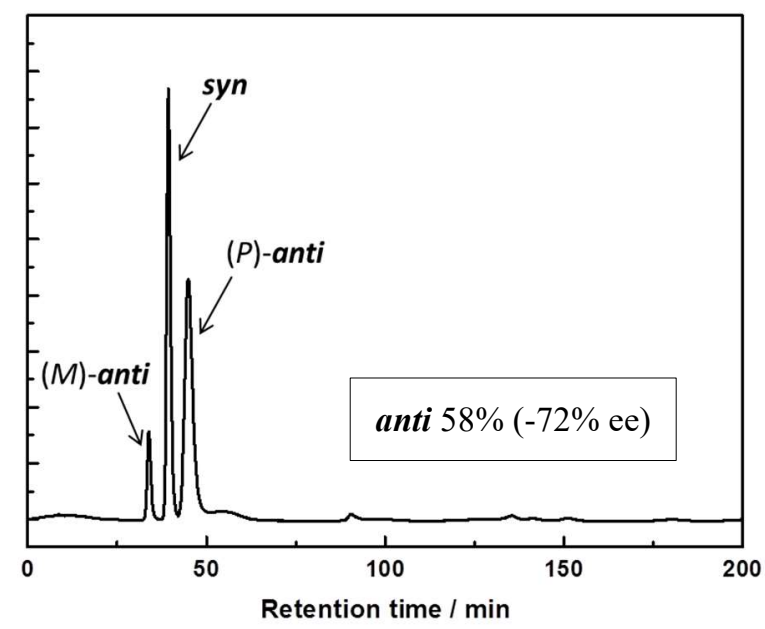

Figure S15. Chiral HPLC trace of the photolyzate ([AD] $=$ $0.4 \mathrm{mM}$, [4] $=2 \mathrm{mM}$; irradiation $\lambda=360 \mathrm{~nm}$; solvent $=1: 1$ mixture of phosphate buffer ( $\mathrm{pH} 9)$ and methanol; $T=-50{ }^{\circ} \mathrm{C}$ ) monitored by a fluorescence detector $\left(\lambda_{\mathrm{ex}}=254 \mathrm{~nm}, \lambda_{\mathrm{em}}=\right.$ $420 \mathrm{~nm})$.

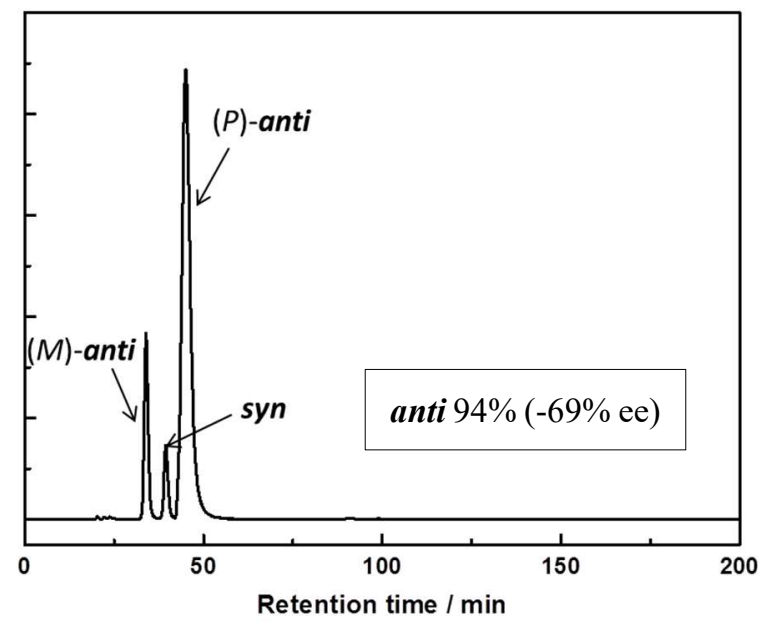

Figure S16. Chiral HPLC trace of the photolyzate ([AD] $=$ $0.4 \mathrm{mM},[5]=2 \mathrm{mM}$; irradiation $\lambda=450 \mathrm{~nm}$; solvent $=28 \%$ aqueous ammonia; $T=-60^{\circ} \mathrm{C}$ ) monitored by a fluorescence detector $\left(\lambda_{\mathrm{ex}}=254 \mathrm{~nm}, \lambda_{\mathrm{em}}=420 \mathrm{~nm}\right)$. 


\section{Population of and light absorption by free AD, $1: 1$ and 1:2 complexes}

Table S1. Population of and light absorption by free AD, 1:1 and 1:2 complexes calculated for a pH 9 phosphate buffer solution of host $\mathbf{1}$ and $\mathbf{A D}$ at $25^{\circ} \mathrm{C}$

\begin{tabular}{|c|c|c|c|c|c|c|c|}
\hline \multirow{2}{*}[\mathbf{AD}]{$/ \mathrm{mM}$} & \multirow{2}{*}[1]{$/ \mathrm{mM}$} & \multicolumn{3}{|c|}{ Population $^{a} / \%$} & \multicolumn{3}{|c|}{ Light absorption ${ }^{b} / \%$} \\
\hline & & Free AD & 1:1 complex & 1:2 complex & Free AD & 1:1 complex & 1:2 complex \\
\hline 0.4 & 2.0 & 51.9 & 18.3 & 29.8 & 40.0 & 14.1 & 45.9 \\
\hline \multirow[t]{16}{*}{0.2} & 0.008 & 99.6 & 0.1 & 0.3 & 99.3 & 0.1 & 0.5 \\
\hline & 0.040 & 98.0 & 0.7 & 1.3 & 96.7 & 0.7 & 2.6 \\
\hline & 0.080 & 96.2 & 1.3 & 2.5 & 93.8 & 1.3 & 4.9 \\
\hline & 0.119 & 94.5 & 1.9 & 3.6 & 91.2 & 1.9 & 7.0 \\
\hline & 0.158 & 92.5 & 2.5 & 4.6 & 88.8 & 2.4 & 8.8 \\
\hline & 0.197 & 91.4 & 3.1 & 5.5 & 86.5 & 3.0 & 10.5 \\
\hline & 0.236 & 89.9 & 3.7 & 6.4 & 84.5 & 3.5 & 12.0 \\
\hline & 0.294 & 87.9 & 4.5 & 7.6 & 81.7 & 4.2 & 14.1 \\
\hline & 0.370 & 85.5 & 5.6 & 8.9 & 78.4 & 5.1 & 16.4 \\
\hline & 0.444 & 83.3 & 6.5 & 10.1 & 75.7 & 6.0 & 18.4 \\
\hline & 0.518 & 81.3 & 7.5 & 11.2 & 73.2 & 6.7 & 20.1 \\
\hline & 0.592 & 79.5 & 8.4 & 12.1 & 70.9 & 7.5 & 21.6 \\
\hline & 0.735 & 76.3 & 10.0 & 13.7 & 67.0 & 8.8 & 24.1 \\
\hline & 1.078 & 69.8 & 13.6 & 16.6 & 59.8 & 11.7 & 28.5 \\
\hline & 1.705 & 61.1 & 19.1 & 19.8 & 51.0 & 15.9 & 33.1 \\
\hline & 2.265 & 55.4 & 23.1 & 21.5 & 45.6 & 19.0 & 35.4 \\
\hline
\end{tabular}

${ }^{a}$ Calculated by using $K_{1}=190 \mathrm{M}^{-1}$ and $K_{2}=10200 \mathrm{M}^{-1}$ (Figure S12). ${ }^{b}$ Fraction of photons absorbed by each AD-containing species, where the 1:2 complex, carrying two $\mathbf{A D s}$, is assumed to absorb twice larger number of photons than free $\mathbf{A D}$ and the $1: 1$ complex, i.e., $\boldsymbol{\varepsilon}_{1: 2} \approx 2 \boldsymbol{\varepsilon}_{\mathbf{A D}}$ $\approx 2 \varepsilon_{1: 1}$. 


\section{Enantiodifferentiating photocyclodimerization of AD mediated by native and modified $\gamma$-CDs}

Table S2. Photocyclodimerization of AD mediated by native and modified $\gamma$-CDs 1-5 (full list) ${ }^{a}$

\begin{tabular}{|c|c|c|c|c|c|c|c|c|c|}
\hline \multirow{2}{*}{ Entry } & \multirow{2}{*}{ Host } & \multirow{2}{*}{ Solvent ${ }^{b}$} & \multirow{2}{*}{$T /{ }^{\circ} \mathrm{C}$} & \multirow{2}{*}{$\lambda c / \mathrm{nm}$} & \multirow{2}{*}{$\begin{array}{l}\text { Irrad. time } \\
/ / \mathrm{min}\end{array}$} & \multicolumn{3}{|c|}{ Yield $(e e)^{e} / \%$} & \multirow{2}{*}{ anti/syn } \\
\hline & & & & & & & tnti & syn & \\
\hline 1 & $\gamma-\mathrm{CD}$ & $\mathrm{B}$ & 0.5 & 254 & 10 & 60.8 & $(-9.7)$ & 39.2 & 1.55 \\
\hline 2 & & & & 270 & 10 & 50.9 & $(-11.9)$ & 49.1 & 1.04 \\
\hline 3 & & & & 280 & 10 & 57.9 & $(-15.8)$ & 42.1 & 1.37 \\
\hline 4 & & & & 290 & 10 & 58.9 & $(-16.9)$ & 41.1 & 1.43 \\
\hline 5 & & & & 300 & 10 & 49.6 & $(-14.9)$ & 50.4 & 0.99 \\
\hline 6 & & & & 313 & 10 & 55.1 & $(-18.0)$ & 44.9 & 1.23 \\
\hline 7 & & & & 350 & 10 & 57.7 & $(-11.1)$ & 42.3 & 1.36 \\
\hline 8 & & & & 360 & 10 & 57.3 & $(-9.7)$ & 42.7 & 1.34 \\
\hline 9 & & & & 380 & 10 & 57.5 & $(-11.2)$ & 42.5 & 1.35 \\
\hline 10 & & & & 390 & 10 & 61.1 & $(-10.3)$ & 38.9 & 1.57 \\
\hline 11 & & & & 400 & 10 & 60.1 & $(-10.9)$ & 39.9 & 1.50 \\
\hline 12 & & & & 420 & 10 & 69.1 & $(-12.6)$ & 30.9 & 2.24 \\
\hline 13 & & & & 430 & 10 & 76.4 & $(-12.2)$ & 23.6 & 3.24 \\
\hline 14 & & & & 440 & 10 & 83.5 & $(-10.2)$ & 16.5 & 5.06 \\
\hline 15 & 1 & $\mathrm{~B}$ & 0.5 & 313 & 10 & 41.2 & $(-21.4)$ & 58.8 & 0.70 \\
\hline 16 & & & & 380 & 10 & 50.2 & $(-19.6)$ & 49.8 & 1.01 \\
\hline 17 & & & & 400 & 10 & 49.8 & $(-19.0)$ & 50.2 & 0.99 \\
\hline 18 & & & & 440 & 10 & 72.6 & $(-16.2)$ & 27.4 & 2.65 \\
\hline 19 & 2 & B & 0.5 & 313 & 10 & 49.3 & $(-22.7)$ & 50.7 & 0.97 \\
\hline 20 & & & & 380 & 10 & 54.8 & $(-19.4)$ & 45.2 & 1.21 \\
\hline 21 & & & & 400 & 10 & 57.0 & $(-18.4)$ & 43.0 & 1.32 \\
\hline 22 & & & & 440 & 10 & 81.5 & $(-9.6)$ & 18.5 & 4.40 \\
\hline 23 & 3 & B & 0.5 & 313 & 10 & 47.4 & $(-21.4)$ & 52.6 & 0.90 \\
\hline 24 & & & & 390 & 10 & 55.0 & $(-19.8)$ & 45.0 & 1.22 \\
\hline 25 & & & & 440 & 10 & 79.4 & $(-15.1)$ & 20.6 & 3.85 \\
\hline 26 & 4 & B & 0.5 & 313 & 10 & 29.2 & $(-30.7)$ & 70.8 & 0.41 \\
\hline 27 & & M & -50 & 313 & 60 & 62.7 & $(-70.5)$ & 37.3 & 1.68 \\
\hline 28 & & & & 360 & 60 & 57.5 & $(-72.0)$ & 42.5 & 1.35 \\
\hline 29 & & & & 450 & 60 & 58.4 & $(-52.6)$ & 41.6 & 1.40 \\
\hline 30 & 5 & M & -40 & 254 & 60 & 71.4 & $(-29.6)$ & 28.6 & 2.49 \\
\hline 31 & & & & 270 & 60 & 65.7 & $(-30.3)$ & 34.3 & 1.91 \\
\hline 32 & & & & 290 & 60 & 66.5 & $(-38.6)$ & 33.5 & 1.98 \\
\hline 33 & & & & 313 & 60 & 62.5 & $(-38.5)$ & 37.5 & 1.67 \\
\hline 34 & & & & 360 & 60 & 64.3 & $(-31.7)$ & 35.7 & 1.80 \\
\hline 35 & & & & 380 & 60 & 63.7 & $(-30.6)$ & 36.3 & 1.76 \\
\hline 36 & & & & 400 & 60 & 61.4 & $(-27.8)$ & 38.6 & 1.59 \\
\hline 37 & & & & 420 & 60 & 72.2 & $(-30.9)$ & 27.8 & 2.60 \\
\hline 38 & & & & 440 & 60 & 86.6 & $(-22.4)$ & 13.4 & 6.45 \\
\hline 39 & & A & 0.5 & 290 & 10 & 67.4 & $(-50.3)$ & 32.6 & 2.06 \\
\hline 40 & & & & 313 & 10 & 64.1 & $(-45.8)$ & 35.9 & 1.79 \\
\hline 41 & & & & 360 & 10 & 66.2 & $(-45.0)$ & 33.8 & 1.96 \\
\hline 42 & & & & 440 & 10 & 88.5 & $(-45.0)$ & 11.5 & 7.71 \\
\hline 43 & & & -60 & 290 & 60 & 63.8 & $(-52.1)$ & 36.2 & 1.76 \\
\hline 44 & & & & 313 & 60 & 64.5 & $(-60.7)$ & 35.5 & 1.81 \\
\hline 45 & & & & 360 & 60 & 67.3 & $(-61.3)$ & 32.7 & 2.06 \\
\hline 46 & & & & 440 & 60 & 83.9 & $(-58.7)$ & 16.1 & 5.21 \\
\hline 47 & & & & 450 & 60 & 93.8 & $(-69.1)$ & 6.2 & 15.08 \\
\hline
\end{tabular}

${ }^{a}[\mathbf{A D}]=0.4 \mathrm{mM} ;[$ host $]=2 \mathrm{mM}$; irradiated by an ultrahigh-pressure Xe lamp through a band-pass filter (fwhm $\left.=10 \mathrm{~nm}\right) .{ }^{b}$ Solvent B: $\mathrm{pH} 9$ phosphate buffer; solvent M: a 1:1 mixture of phosphate buffer $\left(\mathrm{pH}\right.$ 9) and methanol; solvent A: $28 \%$ aqueous ammonia. ${ }^{c}$ Irradiation wavelength. ${ }^{d}$ Chemical yield and enantiomeric excess (in the parentheses) determined by chiral HPLC. Negative ee value indicates the preferential formation of the second-eluted $(P)$-enantiomer of anti under the HPLC conditions employed (i.e., tandem Nacalai Cosmosil 5C18AR-II + Daicel Chiralcel OJ-RH column eluted with a 76:24:0.1 mixture of $\mathrm{H}_{2} \mathrm{O}, \mathrm{MeCN}$ and $\mathrm{CF}_{3} \mathrm{CO}_{2} \mathrm{H}$ ); error in ee $<1 \%$. 


\section{Wavelength-dependent yield and ee of anti}

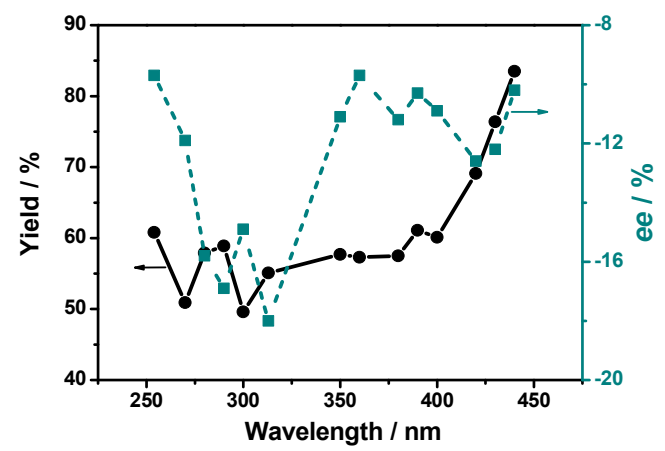

Figure S17. The chemical yield $(\mathbf{O})$ and $e e(\boldsymbol{\square})$ of anti as a function of wavelength upon irradiation of $\mathbf{A D}$ with native $\gamma$-CD in a pH 9.0 phosphate buffer at $25^{\circ} \mathrm{C}$; for the original data, see Table S1 (entries 1-14).

(1) K. Fujita, T. Tahara, T. Imoto and T. Koga, Chem. Lett. 1988, 8, 1329-1332.

(2) C. Yang, G. Fukuhara, A. Nakamura, Y. Origane, K. Fujita, D.-Q. Yuan, T. Mori, T. Wada and Y. Inoue, $J$. Photochem. Photobiol., A: Chem. 2005, 173, 375-383.

(3) C. Ke, C. Yang, T. Mori, T. Wada, Y. Liu and Y. Inoue,
12. Host-guest interactions in the precursor $1: 2$ complex of AD with dicationic $\gamma$-CD host

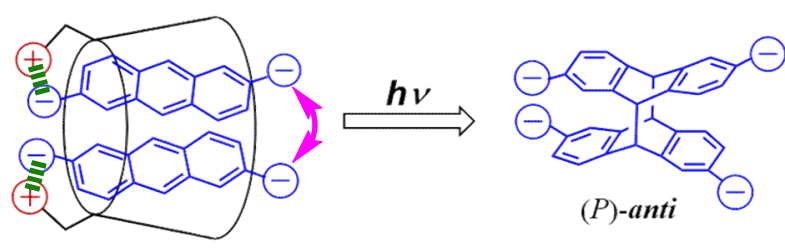

Figure S18. A plausible explanation for the enhanced regioand enantioselectivities achieved upon photocyclodimerization of dianionic AD (versus monoanionic AC) mediated by dicationic $\gamma$-CD (4 and 5) through the attractive host-guest interactions (green) and the repulsive inter-guest interaction (magenta) in the precursor 1:2 complex (left).

Angew. Chem. Int. Ed., 2009, 48, 6675-6677.

(4) Yao, J.; Yan, Z.; Ji, J.; Wu, W.; Yang, C.; Nishijima, M.; Fukuhara, G.; Mori, T.; Inoue, Y. J. Am. Chem. Soc. 2014, 136, 6916-6919.

(5) A. Nakamura and Y. Inoue, J. Am. Chem. Soc. 2003, 125, 966-972. 